Wiener Klinisches Magazin 2013 · 16:2

DOI 10.1007/s00740-013-0103-x

C) Springer-Verlag Wien 2013

\author{
V. Kienast \\ Springer Verlag/Wien, Editor
}

\title{
Vom Hohelied zum Klagelied
}

Die aktuelle Wirtschaftskrise wirft ein bezeichnendes Licht auf das Verantwortungsbewusstsein und die Solidarität der Menschen. Da stehen die Einzelinteressen, die zu den sattsam bekannten Ausreißern in der Gehaltsstruktur in geradezu unglaubliche Höhen führen, und auf der anderen Seite der ökonomischen Hierarchie zu einer immer breiter werdenden Basis, die sich das Leben nicht mehr leisten kann. Extrem hohe Arbeitslosigkeit in den besonders stark betroffenen Ländern und da wiederum ganz besonders unter den jungen Menschen, große Zahlen von Delogierungen oder auch Stromabschaltungen, weil die Energierechnungen nicht mehr bezahlt werden können sind nicht nur ein materielles sondern auch ein moralisches Armutszeugnis für eine Gesellschaft, die immer wieder darauf pocht, dass sie vom christlichen Erbe geprägt ist. Auf der Strecke bleibt - wieder einmal die Menschlichkeit.

\section{Sparen am Sozialsystem}

Einer der ersten Anküpfungspunkte für Sparmaßnahmen ist in solchen Situationen der Sozialstaat, also staatliche Leistungen, die gerade jenen besonders zugute kommen, die materiell schlechter gestellt sind. Überbrückungshilfen bei Arbeitslosigkeit, staatliche Pensionen und nicht zuletzt das Gesundheitssystem werden reduziert. Wer für den Arztbesuch bezahlen muss, und sich das nicht mehr leisten kann, wird längerfristig eine schlechtere Gesundheit aufweisen. Die in Österreich als so selbstverständlich hingenommene flächendeckende Sozialversicherung - mit nur gringen Lücken - ist schon bekanntlich in den USA nach wie vor nicht
Realität. Früherkennung und erfolgreiche Behandlung von möglicherweise andernfalls tödlich verlaufenden Erkrankungen wird möglich - oder scheitert am Zugang zum Medizinsystem.

\section{Krise als Zäsur}

Während aber auf der einen Seite, die Vermögenden noch versuchen ihre Schätze zu retten - in Griechenland ebenso wie in Italien oder kürzlich in Zypern - und die Mehrheit der Bevölkerung zwischen Zorn und Verzweiflung hin- und hergerissen ist, lassen sich auch immer wieder Initiativen beobachten, die die Hoffnung auf eine Weiterentwicklung der Menschheit aus den archaischen Verhaltensmustern von Jagen und Sammeln nicht ganz aufgeben lassen. Ob dies Ärzte sind, die bis zur Erschöpfung kostenlos bedürftige Patienten behandeln, oder junge Künstler, die ihren Unmut in Kreativität umsetzen.

Ganz verloren gegangen ist die Solidarität also nicht, sie bedarf allerdings oft ziemlich schmerzhafter eigener Betroffenheit. Auf EU-Ebene scheint sie noch nicht angekommen zu sein, wenn man die Reaktionen der noch nicht so hart getroffenen Staaten und breiter Bevölkerungsschichten dort beobachtet, die freilich häufig von populistisch agierenden politischen Parteien leicht beeinflussbar sind. Dabei wäre die Rückbesinnung auf immaterielle Werte und die Schönheit des Augenblicks und auf die Freude an der Freude des Gegenüber ein reicher Gegenpol zur Anhäufung von Besitz und dem Streben nach Vermehrung. Der Kapitalismus dagegen hat uns, wie der Schriftsteller Peter Rosei kürzlich in einem Radiointerview so treffend feststellte, mit seiner
Ausrichtung auf eine immer noch bessere Zukunft, die Gegenwart genommen. Die Wertschätzung des Augenblicks und die innere Verbundenheit als Teil eines umfassenden Ganzen aber scheint einer der Schlüssel zum sinnvollen Leben zu sein. Das gilt nicht nur im Zen-Buddhismus.

\section{Polarisierung der Gesellschaft}

Der unbedingte Primat der Wirtschaft und Wirtschaftlichkeit führt zu Absurditäten und Verschärfungen. Wenn Pensionen durch mehr oder minder riskante Spekulationen und durch beispielsweise Immobilieninvestitionen mit überdurchschnittlichen Renditen gesichert werden sollen, beißt sich die Katze in den Schwanz und die Gesellschaft wird weiter polarisiert. Das Hohelied auf rücksichtlose Einzelkämpfer wird langfristig allerdings ein Klagelied werden

meint Ihre

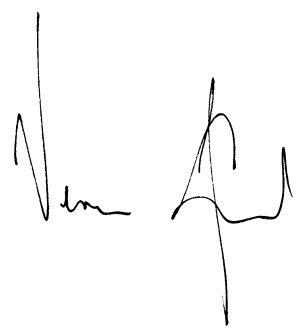

Verena Kienast

Springer-Verlag GmbH SpringerMedizin/Editor verena.kienastspringer.at 